University of Nebraska - Lincoln

DigitalCommons@University of Nebraska - Lincoln

\title{
Dynamic Response of Brain Subjected to Blast Loadings: Influence of Frequency Ranges
}

\author{
Mehdi S. Chafi \\ University of Nebraska-Lincoln, msotudeh@gmail.com \\ Shailesh G. Ganpule \\ University of Nebraska-Lincoln \\ Linxia Gu \\ University of Nebraska-Lincoln, gul@fit.edu \\ Namas Chandra \\ University of Nebraska-Lincoln, nchandra2@unl.edu
}

Follow this and additional works at: https://digitalcommons.unl.edu/mechengfacpub

Part of the Mechanical Engineering Commons

Chafi, Mehdi S.; Ganpule, Shailesh G.; Gu, Linxia; and Chandra, Namas, "Dynamic Response of Brain Subjected to Blast Loadings: Influence of Frequency Ranges" (2011). Mechanical \& Materials Engineering Faculty Publications. 60.

https://digitalcommons.unl.edu/mechengfacpub/60

This Article is brought to you for free and open access by the Mechanical \& Materials Engineering, Department of at DigitalCommons@University of Nebraska - Lincoln. It has been accepted for inclusion in Mechanical \& Materials Engineering Faculty Publications by an authorized administrator of DigitalCommons@University of Nebraska Lincoln. 


\title{
Dynamic Response of Brain Subjected to Blast Loadings: Influence of Frequency Ranges
}

\author{
Mehdi S. Chafi, ${ }^{1}$ Shailesh Ganpule, ${ }^{1}$ \\ Linxia $\mathrm{Gu}^{1,2}$ and Namas Chandra ${ }^{1}$ \\ 1. Department of Mechanical and Materials Engineering, \\ University of Nebraska-Lincoln, Lincoln NE 68588-0656, USA \\ 2. Nebraska Center for Materials and Nanoscience, Lincoln NE 68588-0656, USA \\ Corresponding author - L. Gu, email lgu2@unl.edu
}

\begin{abstract}
Blast wave induced a frequency spectrum and large deformation of the brain tissue. In this study, new material parameters for the brain material are determined from the experimental data pertaining to these large strain amplitudes and wide frequencies ranging (from $0.01 \mathrm{~Hz}$ to $10 \mathrm{MHz}$ ) using genetic algorithms. Both hyperelastic and viscoelastic behavior of the brain are implemented into 2D finite element models and the dynamic responses of brain are evaluated. The head, composed of triple layers of the skull, including two cortical layers and a middle dipole sponge-like layer, the dura, cerebrospinal fluid (CSF), the pia mater and the brain, is utilized to assess the effects of material model. The results elucidated that frequency ranges of the material play an important role in the dynamic response of the brain under blast loading conditions. An appropriate material model of the brain is essential to predict the blast-induced brain injury.
\end{abstract}

Keywords: Brain, hyper-viscoelastic material model, high frequency, finite strain, blast wave

\section{Introduction}

Complete understanding of mild traumatic brain injuries (TBI) induced by blast waves is challenging, due to the fact that currently no medical diagnostic tools could indicate the onset of the ailment [Hoge et al., 2008]. Finite element (FE) modeling has been widely used to predict the blast-induced brain responses and better understand the mechanism of TBIs [Moore et al., 2009; Moss et al., 2009; Taylor et al., 2009; Chafi et al., 2010; Ganpule et al., 2010; Grujicic et al., 2010]. The numerical predictions depends on the appropriate material characterization under blast loading conditions. 
Brain material is strain- and frequency-dependent [Bilston et al., 2001]. Blast scenarios require knowledge of brain tissue behavior over a large strain/high frequency range [Pervin and Chen, 2009]. Current experimental research has focused on the large strain/low frequency or small strain/high frequency behavior of the tissue, as summarized in Table 1. Some material models are based on hyperviscoelastic assumptions, i.e., a linear viscoelastic model in conjunction with a nonlinear hyperelastic model [Darvish and Crandall, 2001; Mendis et al., 1995; Miller, 1997; Nicolle et al., 2005; Prange and Margulies, 2002; Takhounts et al., 2003]. The large strain/high frequency behavior of brain tissue is newly added into this database [Pervin and Chen, 2009]. However, documented FE models (Table 2) have not been updated yet to reflect the new experimental data in predicting human head/brain behavior under blast conditions. Computational analyses of dynamic response of the brain under blast conditions only covered the low frequency response $(<200 \mathrm{~Hz})$ and neglected the critical high frequency regime [Chafi et al., 2010; Moore et al., 2009; Taylor and Ford, 2009]. No material model of the brain under blast scenario, corresponding to a wide range of frequencies $(0.01 \mathrm{~Hz}-10 \mathrm{MHz})$ along with finite strain, has been presented in the literature, which is critical to better predict the response of the head under blast conditions and improve the TBI prevention.

In this study, a finite strain material model of the brain was developed to cover a wide range of frequencies $(0.01 \mathrm{~Hz}-10 \mathrm{MHz})$. Different experimental studies on the brain tissue were combined to obtain master curves in compression and shear. The material coefficients were determined from curve fitting using genetic algorithms (GAs). The influence of this new material model, as well as the effect of viscoelasticity and hyperelasticity was evaluated through the brain's dynamic responses subjected to the blast loading.

\section{Material Model of Brain Tissue}

Brain properties are affected by a variety of factors, such as testing modes, strain rates, frequency ranges, specimen preparations, species, regional differences, local anisotropy, tissue freshness, and so on [Gefen et al., 2004; Nicolle et al., 2004]. The mechanical properties of fresh human brain tissue was reported to be nearly $30 \%$ stiffer than that of porcine or bovine brain tissue under the same test conditions [Takhounts et al., 2003]. Recently, Pervin and Chen [2011] conducted uniaxial compression tests over a wide range of strain rates on the fresh brain tissue of porcine, bovine, and caprine origin using a conventional hydraulic test frame. No significant difference was found in the compressive response of the brain tissue of different species. However, all the brain tissues showed significant sensitivity to the applied strain rates.

The blast scenario generally leads to brain tissue undergoing a finite strain over a wide frequency range. A hyper-viscoelastic material model was developed for the brain by combining different sets of experimental data [Franceschini et al., 2006; Pervin and Chen, 2009; Bilston et al., 1997; Nicolle et al., 2005; Brands et al., 







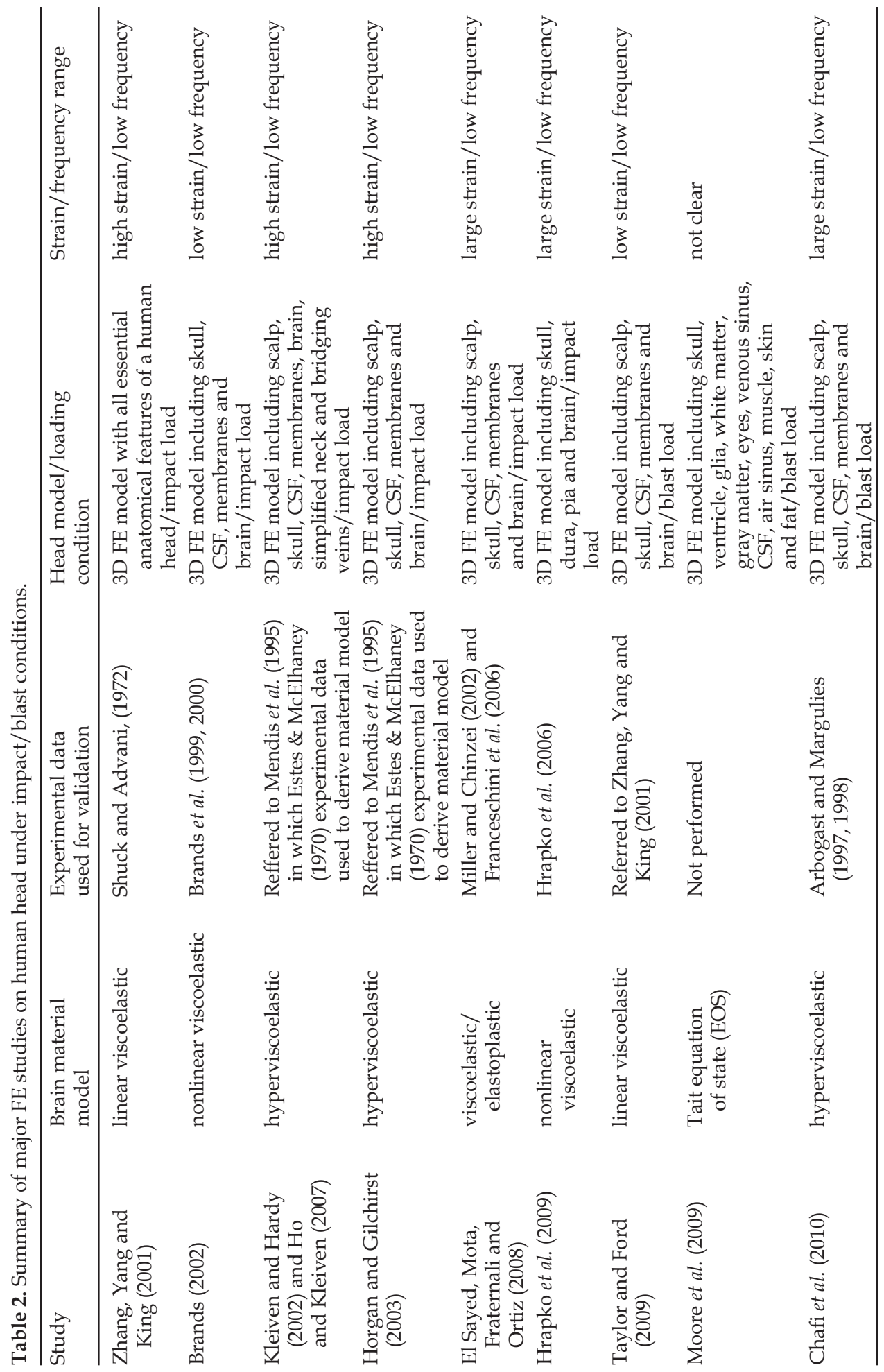


2000; Arbogast and Margulies, 1997, 1998; Lippert et al., 2004; Shuck and Advani, 1972]. The constitutive models are formulated in terms of a viscoelastic framework, considering linear viscous deformations in combination with nonlinear hyperelastic behavior. The total Cauchy stress tensor is the summation of both viscoelastic and hyperelastic induced stress.

Two hyperelastic material models were developed in this work to describe the strain-dependent mechanical properties of brain tissue. The models are based on a two-term Ogden strain energy density function and a Mooney-Rivlin model, respectively. The Ogden model assumes that the strain energy density is a separate function of three principal stretches as (for incompressible materials):

$$
W=W\left(\lambda_{1}, \lambda_{2}, \lambda_{3}\right)=\sum_{i=1}^{N} \frac{\mu_{i}}{a_{i}}\left(\lambda_{1}^{a_{i}}+\lambda_{2}^{a_{i}}+\lambda_{3}^{a_{i}}-3\right),
$$

where $\lambda_{1}, \lambda_{2}$, and $\lambda_{3}$ are the principal stretch ratios and $\mu_{i}$ and $a_{i}$ are constants to be determined experimentally for every value of $i$. Once $W$ is defined, the Cauchy stress created in the tissue by its elastic contribution can be calculated by taking the derivative with respect to strain,

$$
\sigma_{i}=-p+\lambda_{i} \frac{\partial W}{\partial \lambda_{i}}
$$

where $\sigma$ is the Cauchy stress tensor. Only one index is used for the stress tensor since the derivative of $W$, with respect to the principal stretch tensors, gives the principal stresses. Four Ogden parameters were determined from the two experimental resources reported by Franceschini et al. [2006] and Pervin and Chen [2009]. An optimization approach based on GAs has been used to determine the material parameters from the experimental data. The obtained parameters are shown in the second and third columns of Table 3. A comparison between experimental and fitted stress-strain curves is shown in Figure 1.

For the Mooney-Rivlin model, the strain energy function is defined as a polynomial function of the principal strain invariants as (for incompressible material)

$$
W=C_{10}\left(I_{1}-3\right)+C_{01}\left(I_{2}-3\right)
$$

where $W$ is the strain energy potential; $C_{10}$ and $C_{01}$ are material constants; $I_{1}$ and $I_{2}$ are the first and second principal stress invariants. A long-term shear modulus from the viscoelastic experimental data are used to obtain $C_{10}$ and $C_{01}$ which in

Table 3. Hyperelastic material parameters fitted to experiments [Pervin and Chen, 2009; Franceschini et al., 2006].

\begin{tabular}{llll}
\hline $\begin{array}{l}\text { Brain's } \\
\text { constitutive law }\end{array}$ & $\begin{array}{l}\text { Ogden model- } \\
\text { Pervin } \text { et al., 2009 }\end{array}$ & $\begin{array}{l}\text { Ogden model- } \\
\text { Franceschini } \text { et al., 2006 }\end{array}$ & $\begin{array}{l}\text { Mooney-Rivlin } \\
\text { model }\end{array}$ \\
\hline Hyperelastic terms & $\begin{array}{l}\mu_{1}=-132.6 \mathrm{kPa} \\
\mu_{2}=0.481 \mathrm{kPa}\end{array}$ & $\begin{array}{l}\mu_{1}=0.1138 \mathrm{kPa} \\
\mu_{2}=-0.2711 \mathrm{kPa}\end{array}$ & $\begin{array}{l}C_{10}=514.62 \mathrm{~Pa} \\
C_{01}=566.08 \mathrm{~Pa}\end{array}$ \\
$v=0.49999948$ & $a_{1}=0.00374$ & $a_{1}=11.64$ & \\
$K=2.19 \mathrm{GPa}$ & $a 2=10.01$ & $a_{2}=-11.06$ & \\
\hline
\end{tabular}






Figure 1. Nonlinear hyperelastic behavior of the brain tissue (experimental-1 source: Pervin and Chen, 2009; experimental-2 source: Franceschini et al., 2006).

turn is derived from $\sigma \mu_{i} a_{i} / 2$. The relation adopted by Mendis [Mendis et al., 1995] is used between $G_{\infty^{\prime}} C_{10^{\prime}}$ and $C_{01}$, thus $G_{\infty}=2\left(C_{10}+C_{01}\right)$, together with $C_{10}=0.9$ $\mathrm{C}_{01}$. Poisson's ratio is calculated to maintain the bulk modulus at a constant value of $2.19 \mathrm{GPa}$ for the shear modulus of $2160 \mathrm{~Pa}$. The fourth column of Table 3 presents the Mooney-Rivlin model parameters.

Strain rate effects are taken into account using the Maxwell viscoelastic model. The associated Cauchy stress is computed through:

$$
\sigma_{i j}=J^{-1} F_{i k} \cdot S_{k m} \cdot F_{m j}^{T},
$$

where $\sigma_{i j}$ is the Cauchy stress, $F$ is the deformation gradient tensor, $J$ is the Jacobian of transformation, and $S_{i j}$ is the second Piola-Kirchhoff stress, which is estimated using a convolution integral:

$$
S_{i j}=\int_{0}^{t} G_{i j k l}(t-\tau) \frac{\partial E_{k l}}{\partial \tau} d \tau,
$$

where $\partial E_{k l}$ is the Green's strain tensor, and $G_{i j k l}$ is the tensorial stress relaxation function. The relaxation modulus for an isotropic material can be represented by a Prony series:

$$
G(t)=G_{\infty}+\sum_{i=1}^{n} G_{i} e^{-\beta_{i} t},
$$

where $G_{\infty}$ is the long-term modulus and $\beta$ is the decay constant. The relaxation moduli and decay constants are estimated from the experimental data reported by Bilston et al. [1997], Nicolle et al. [2005], Brands et al. [2000], Arbogast and 
Table 4. Viscoelastic material parameters fitted to experiments [Bilston et al., 1997; Nicolle et al., 2005; Brands et al., 2000; Arbogast and Margulies, 1997 and 1998; Lippert et al., 2004; Shuck, Advani, 1972].

\begin{tabular}{ll}
\hline Brain's constitutive law & Frequency range $[0.02 \mathrm{~Hz}-10 \mathrm{MHz}]$ \\
\hline Viscoelastic terms & $\mathrm{G}_{\infty}=2160 \mathrm{~Pa}$ \\
& $\mathrm{G}_{1}=156,488.3 \mathrm{kPa}$ \\
$\mathrm{G}_{2}=326,025.8 \mathrm{kPa}$ \\
$\mathrm{G}_{3}=0.0016 \mathrm{kPa}$ \\
$\mathrm{G}_{4}=1.2313 \mathrm{kPa}$ \\
$\mathrm{G}_{5}=17.583 \mathrm{kPa}$ \\
$\mathrm{G}_{6}=0.0254 \mathrm{kPa}$ \\
$\beta_{1}=1.0763 \mathrm{e}+9 \mathrm{sec}^{-1}$ \\
$\beta_{2}=35.7999 \mathrm{e}+6 \mathrm{sec}^{-1}$ \\
$\beta_{3}=383.5146 \mathrm{e}+3 \mathrm{sec}^{-1}$ \\
$\beta_{4}=1 \mathrm{e}+3 \mathrm{sec}^{-1}$ \\
$\beta_{5}=10 \mathrm{sec}^{-1}$ \\
$\beta_{6}=3.6533 \mathrm{sec}^{-1}$ \\
\hline
\end{tabular}

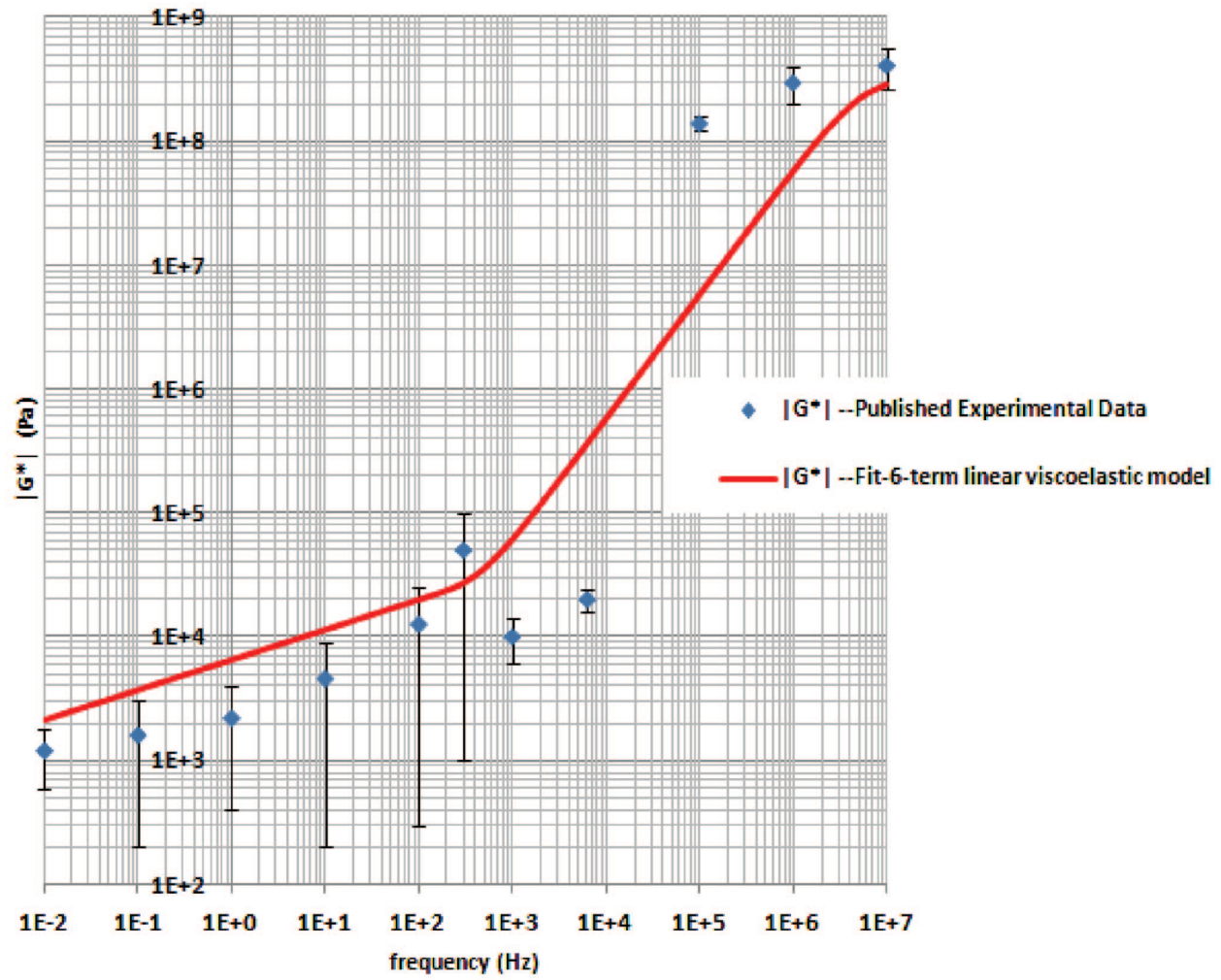

Figure 2. Complex shear modulus - experimental data and the fitted six-term Maxwell viscoelastic model (experimental source: Bilston et al., 1997; Nicolle et al., 2005; Brands et al., 2000; Arbogast and Margulies, 1997, 1998; Lippert et al., 2004; Shuck and Advani, 1972). 
Margulies [1997, 1998], Lippert et al. [2004] and Shuck and Advani [1972], which provide the brain material tests at a wide frequency range between $0.01 \mathrm{~Hz}-10$ $\mathrm{MHz}$. The fitted material parameters are depicted in Table 4. To the best of our knowledge, this is the first material model for the brain that covers such sweeping interval of frequencies. The numerical and experimental data is presented in Figure 2. The long-term shear modulus of the model is $2160 \mathrm{~Pa}$. It is necessary to mention that there would be 15 or 17 material parameters for the entire hyperviscoelastic model depending on the chosen Mooney-Rivlin or Ogden hyperelastic model, respectively. Then the total Cauchy stress is the superimposition of the stress tensor determined from both the hyperelastic strain energy function and the viscoelastic effect.

\section{Finite Element Model}

An explicit nonlinear dynamic FE model has been developed to study the influences of various brain material models in different frequency ranges and strain regimes on the brain's dynamic response under blast loading. The FE model includes the triple layers of the skull (two cortical layers and middle dipole spongelike layer; with a thickness of $4.5 \mathrm{~mm}$ ), the dura (thickness of $1 \mathrm{~mm}$ ), cerebrospinal fluid otherwise known as CSF (thickness of $1.5 \mathrm{~mm}$ ), the pia mater (thickness of $1 \mathrm{~mm}$ ), and the brain. The dimensions of the model are $5 \mathrm{~cm} \times 12 \mathrm{~cm}$ which was meshed with 6700 4-noded plane strain elements.

A summary of the material properties of each head components used in this study is presented in Table 5. These properties are adopted from Kleiven and Hardy [2002], Horgan and Gilchrist [2004], Baumgartner and Willinger [2005] and are consistent with properties reported by Liu et al. [2007]. A three-layered nonhomogeneous material is used to model the skull. The innermost layer that is in contact with the dura mater and the outmost layer are modeled as the same stiff material. Sandwiched in between them is the so-called dipole, in which the Young's modulus is smaller than those of the inner and outermost layers.

A coupled Eulerian and Lagrangian formulation is used to mimic the interaction between the fluid (CSF), pia, and dura maters. A Gruneisen equation of state is used for the CSF with a bulk modulus of 2.19 GPa. An equation of state

Table 5. Material properties of head components used in this study [Kleiven and Hardy, 2002; Horgan and Gilchrist, 2004; Baumgartner and Willinger, 2005].

\begin{tabular}{lccc}
\hline Tissue & Young's modulus E $(\mathrm{MPa})$ & Density $\left(\mathrm{Kg} / \mathrm{m}^{3}\right)$ & Poisson's ratio \\
\hline Pia & 11.5 & 1130 & 0.45 \\
Dura & 31.5 & 1130 & 0.45 \\
Outer Table & 15,000 & 2000 & 0.22 \\
Dipole & 1000 & 1300 & 0.24 \\
Inner Table & 15,000 & 2000 & 0.22 \\
CSF & $K=2.19$ GPa & 1000 & Incompressible \\
Brain & Hyper-viscoelastic & 1040 & $v=0.49999948$ \\
\hline
\end{tabular}


(EOS) determines the hydrostatic behavior of the material by calculating pressure as a function of density, energy, and/or temperature. For the CSF, the Gruneisen equation of state with a cubic shock velocity-particle velocity is used [Ls Dyna, 2006], which defines pressure for a compressed material as:

$$
p=\frac{\rho_{0} C^{2} \mu\left[1+\left(1-\gamma_{0} / 2\right) \mu-a / 2 \mu^{2}\right]}{\left[1-\left(S_{1}-1\right) \mu-S_{2} \mu^{2} /(\mu+1)-S_{3} \mu^{3} /(\mu+1)^{2}\right]}+\left(\gamma_{0}+a \mu\right) E,
$$

where $\mu=\left(\rho / \rho_{0}\right)-1=\left(1 / V_{0}\right)-1$. C and $S_{1}$ are parameters in the shock velocity $\left(v_{s}\right)$ and particle velocity $\left(v_{p}\right)$ according to the relation: $v_{s}=C+S_{1} v_{p}$. C is the intercept of the $v_{s}-v_{p}$ curve, $S_{1}, S_{2}$, and $S_{3}$ are the coefficients of the slope of the $v_{s}-v_{p}$ curve. Additionally, $r_{0}$ is the Gruneisen gamma, $a$ is the first-order volume correction to $\gamma_{0}$, and $E$ is the internal energy. The Gruneisen equation parameters are decided based on bulk modulus and initial density.

The tied contact algorithm is used for the brain-membrane interfaces because it can transfer loads in both compression and tension. If penalty contact algorithm is used, only compressive loads are transferred and a gap will be created in the countertop region where tension loading is possible [Kleiven and Hardy, 2002]. Numerical stability was insured by monitoring the hourglass energy, which is negligible in the blast event since the kinetic energy decreases as the head's internal energy increases.

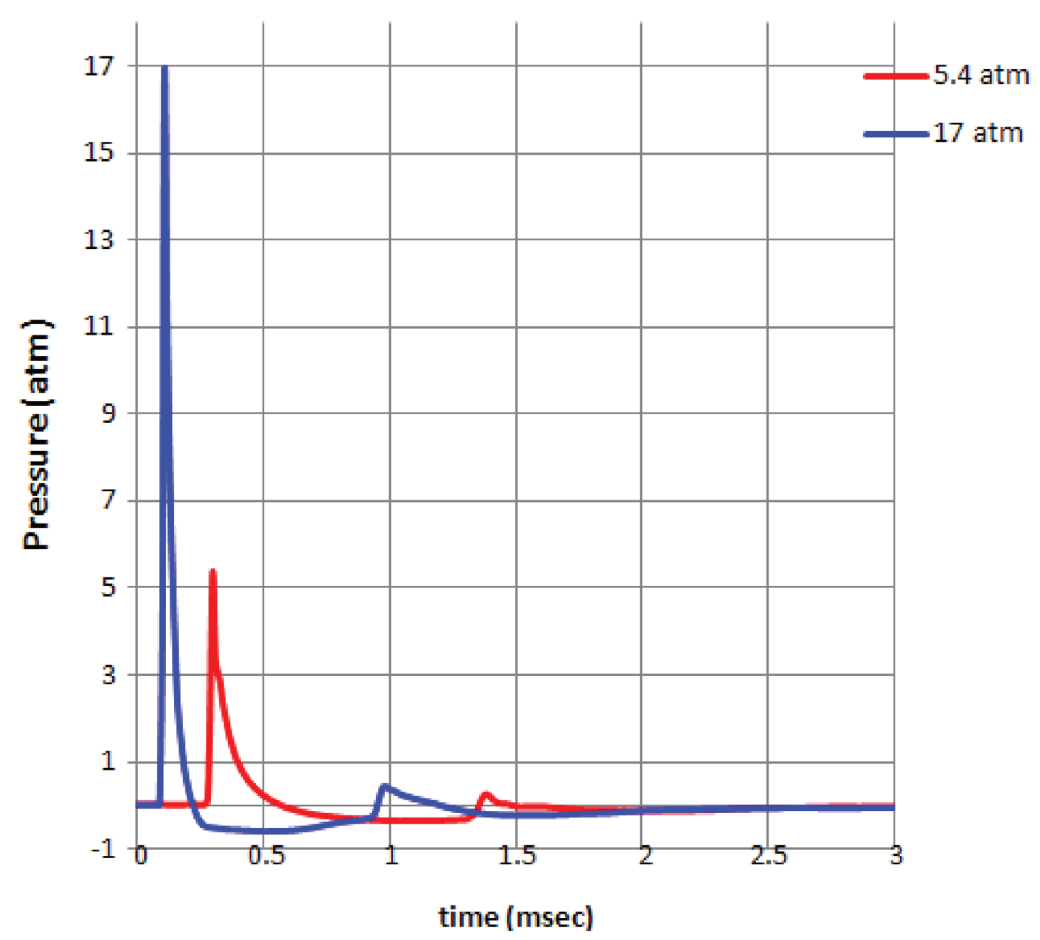

Figure 3. The blast load with $5.4 \mathrm{~atm}$ or $17 \mathrm{~atm}$ peak overpressure obtained from free-air detonation. 
Two different blast scenarios based on blast characteristics, positive pulse duration, and peak overpressure, have been used in this study with reference to the Bowen curves. The applied blast load curve (Figure 3) is obtained from free-air detonation [Chafi et al., 2009]. The peak pressure value of $5.4 \mathrm{~atm}$ and $17 \mathrm{~atm}$ are chosen based on the Bowen curve, which indicates that the threshold for unprotected lung injury is $5.4 \mathrm{~atm}$, and $\mathrm{LD}_{50}$ (lethal dose, $50 \%$ ) meaning an approximately $50 \%$ survival rate from lung injuries incurred at $17 \mathrm{~atm}$ [Bowen et al., 1968].

\section{Results and Discussion}

The intracranial pressure (ICP), shear stresses and strains were suggested as injury predictors for traumatic brain injury. In 1980, Ward et al. [1980] proposed a peak ICP concussion threshold of $235 \mathrm{kPa}$ through animal studies and minor or no brain injury for ICPs below $173 \mathrm{kPa}$. In 1999, Anderson et al. [1999] reported through caprine tests and numerical analysis that shear stresses over the range of 8-16 kPa could cause widespread axonal injuries. In addition, Kang et al. [1997] suggested through computational simulation of motorcyclist accidents, that shear stresses over the range of 11-16.5 kPa could lead to significant brain injury. Morrision et al. [2003] showed that maximum principal strain can be used as a measure of central nervous system (CNS) injuries such as diffuse axonal injury (DAI) and cell death. Bain and Meaney [2000] also demonstrated that DAI is practically a function of distortion (strain), rather than pressure, which maybe a more relevant parameter to predict head injury. They estimated a principal strain threshold for axonal damage of $21 \%$ for morphological axonal injury, and $18 \%$ for deterioration of nerve function, all based on experiments done on optic nerves of adult guinea pigs.

In this work, the dynamic response of the brain was evaluated in terms of ICP, maximum shear stress, and maximum principal strain. The impacts of the frequency range, large strain behavior, and applied loading magnitude and frequency are investigated to demonstrate the efficiency of the new material model.

\subsection{Influences of viscoelasticity on the brain's dynamic responses}

It is speculated by some researchers that the viscoelastic effect of the brain is negligible under high frequency loadings, such as blast [Moore et al., 2009]. To address this issue, we have employed two material models with and without considering viscoelasticity of the brain: one is the Ogden hyperelastic model only, as presented in the third column of Table 3; the other is the corresponding hyperviscoelastic model with the addition of a viscoelastic model presented in Table 4.

A shock wave with the peak pressure of $5.4 \mathrm{~atm}$, as shown in Figure 3, was applied onto the head. The dependence of the brain's dynamic response on the selected material models are demonstrated in Figure 4. The peak ICPs [Figure 4(a)] are almost the same for both material models of the brain, i.e., approximately 215 $\mathrm{kPa}$. However, the damping rate of the ICP varied, and the viscoelasticity led to a faster damping effect. 


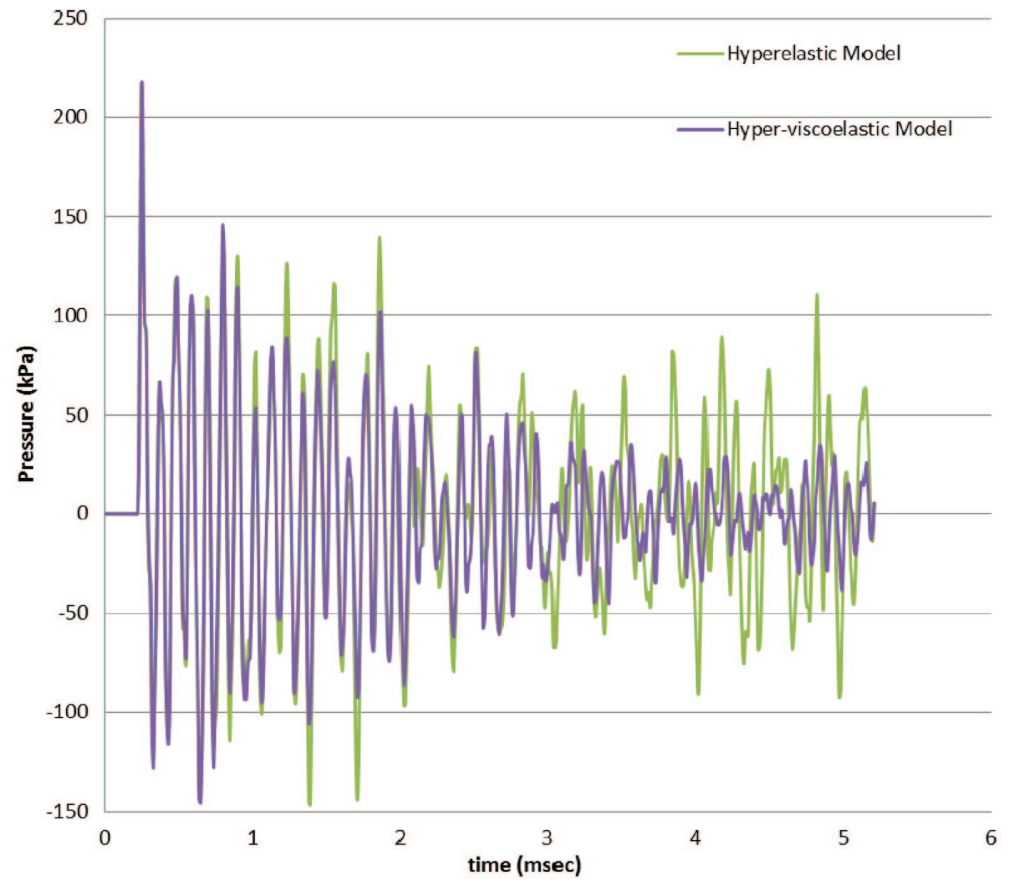

(a)

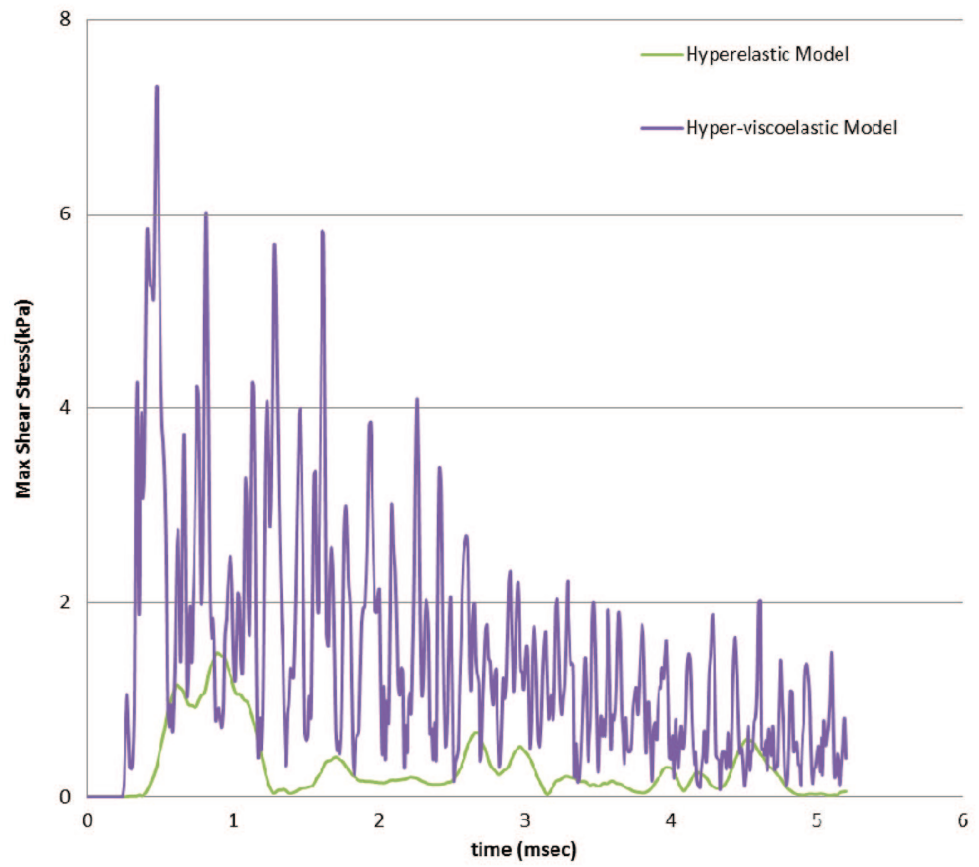

(b)

Figure 4. Influences of viscoelasticity (hyperelastic versus hyper-viscoelastic) on the brain's dynamic responses subjected to a 5.4 atm peak blast overpressure. 


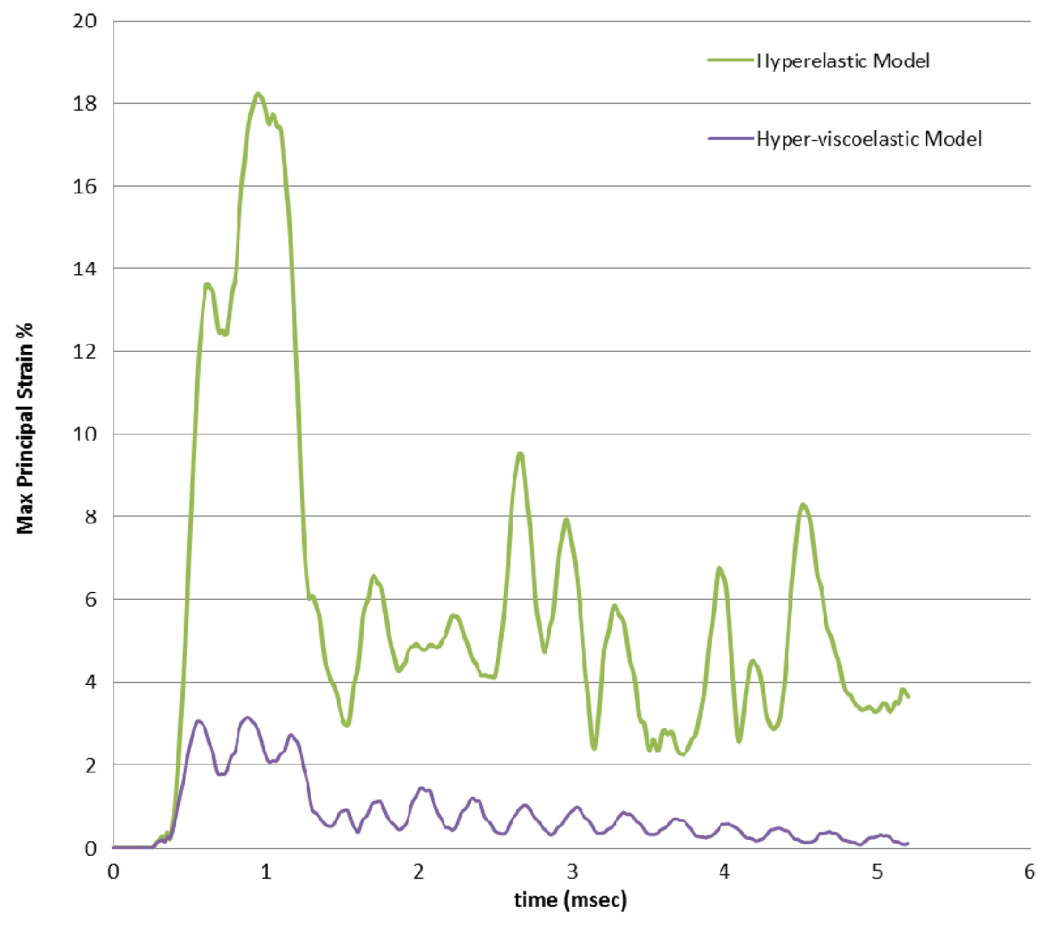

(c)

Figure 4. (continued)

The peak maximum shear stress in the hyper-viscoelastic model far exceeded that of the hyperelastic model [Figure 4(b)]. The opposite behavior is observed for the peak maximum principal strains [Figure 4(c)]. Compared to the results based on the hyperelastic model, the peak shear stress in the hyper-viscoelastic model increased approximately five times, and the peak principal strain was reduced by a factor of nine. This indicates that viscoelastic behavior significantly impacts the shear stress and strain field of the brain. It is important to note that this effect is not observed in the low frequency $(<200 \mathrm{~Hz})$ material model proposed by Moore et al. [2009] who used a material model in which only the volumetric response of brain tissue was described by the Tait EOS, and concluded that in blast scenarios stress relaxation caused by viscoelastic effects can be neglected. Our results herein clearly show that a brain material model under a wide frequency range will have a significant impact on brain dynamics and the predictions of the TBI accordingly.

\subsection{Influences of hyperelasticity on the brain's dynamic responses}

To study the influence of hyperelastic terms on the brain tissue under blast load, two Ogden models and a Mooney-Rivlin model presented in Table 3 were 

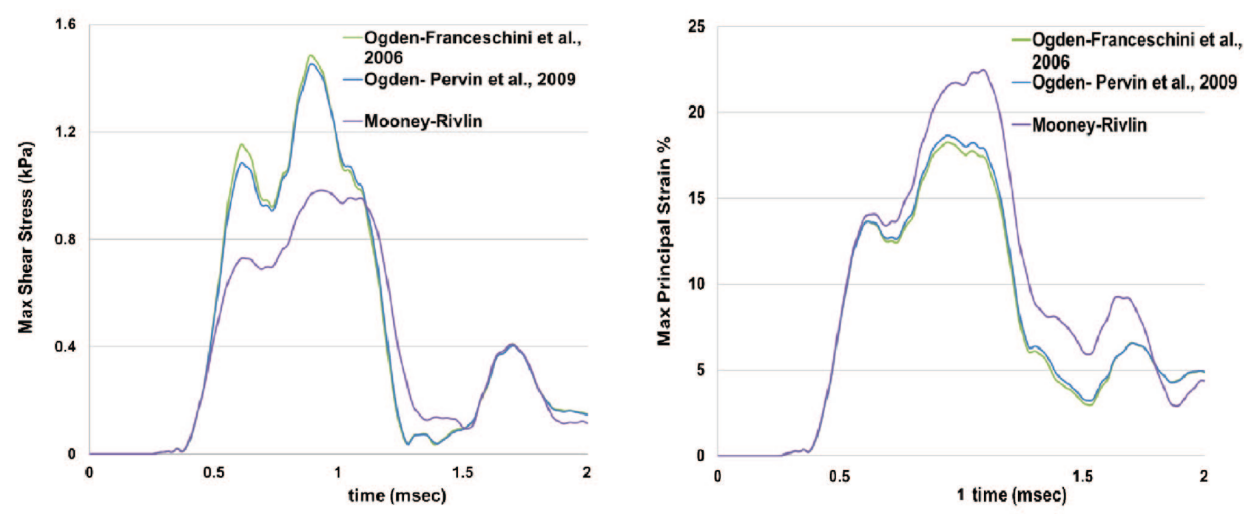

(a)
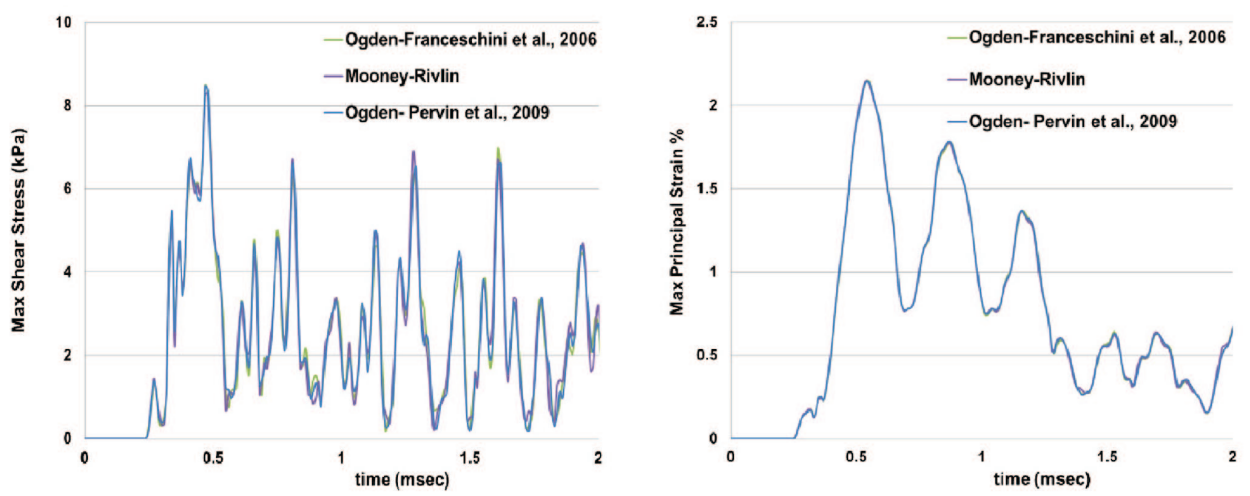

(b)

Figure 5. Dynamic responses of the brain tissue subjected to a $5.4 \mathrm{~atm}$ peak blast overpressure. (a) Influences of hyperelasticity: the brain was described using a hyperelastic constitutive law only, including two Ogden models and one Mooney-Rivlin model presented in Table 3. (b) The dominating viscoelasticity: the brain was described using three hyperelastic materials model presented in Table 3, plus the same viscoelastic model (Table 4).

employed in the simulation of blast induced brain responses. It is clear from Figure 5 that two Ogden models resulted in very similar intracranial dynamic responses in terms of maximum shear stress and principal strain. However, there was a clear difference between Mooney-Rivlin model and the Ogden ones, as shown in Figure 5(a).

Since we found out, in the previous section, that viscoelasticity is important on the prediction of brain responses, a viscoelastic model (Table 4) was then added to the three hyperelastic material models, and forming three hyperviscoelastic constitutive laws. The differences only lie in the hyperelastic behavior. All these three hyperviscoelastic models of the brain demonstrate almost identical brain responses, as shown in Figure 5(b). This indicates that the influence of the hyperelastic term on the dynamic response of the brain is minimal, especially compared to the viscoelastic term. The results suggest that a simple Mooney-Rivlin model would be sufficient to represent the hyperelastic portion of the brain's material model. 




(a)



(b)

Figure 6. Dynamic responses of the brain tissue subjected to $5.4 \mathrm{~atm}$ and $17 \mathrm{~atm}$ peak blast overpressure, respectively. 


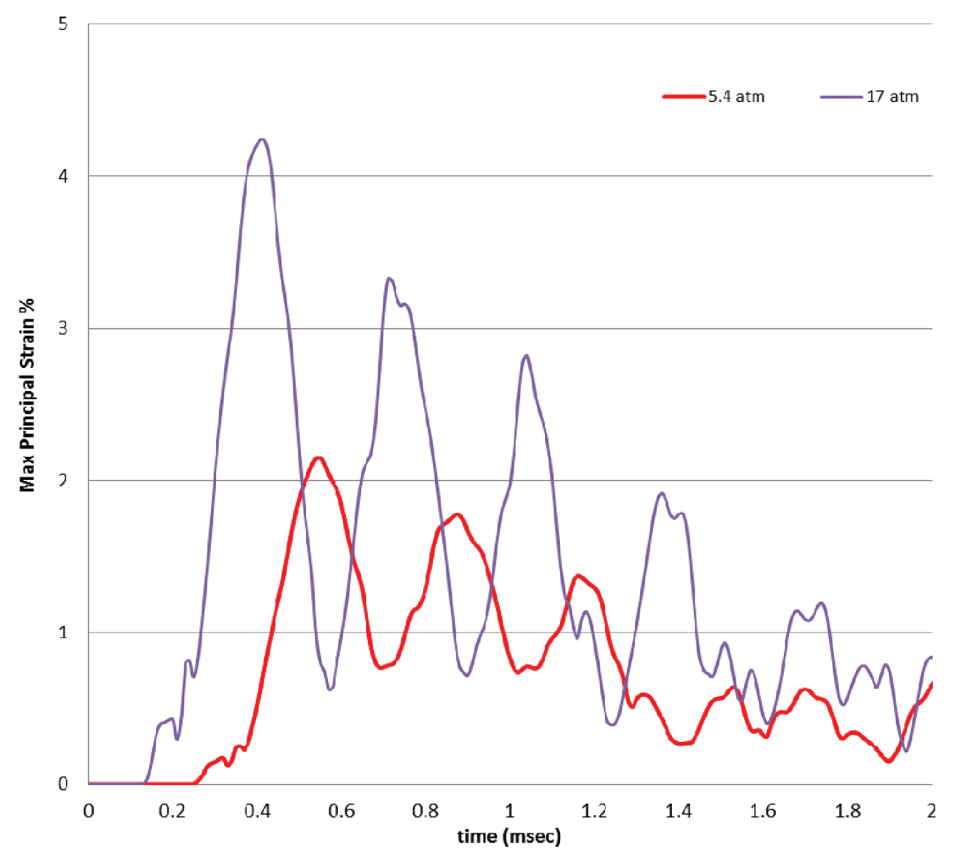

(c)

Figure 6. (continued)

\subsection{Effect of the peak blast overpressure}

Two blast loading conditions as shown in Figure 3 are used to assess the influence of the peak blast overpressure. The dynamic responses of brain tissue, including ICPs, maximum shear stresses and maximum principal strains, subjected to these blast loadings are presented in Figure 6. The ICPs are in the range of -470 $\mathrm{kPa}$ to $640 \mathrm{kPa}$ under applied $17 \mathrm{~atm}$ peak blast overpressure, compared to the range of $-133 \mathrm{kPa}$ to $215 \mathrm{kPa}$ for applied $5.4 \mathrm{~atm}$ peak overpressure. The peak maximum shear stress and maximum principal strain are $18.5 \mathrm{kPa}$ and $4.5 \%$ respectively for applied 17 atm peak overpressure, compared to $8.5 \mathrm{kPa}$ and $2.2 \%$ for the $5.4 \mathrm{~atm}$ overpressure. Based on previously mentioned thresholds for ICP, max shear stress and principal strain, no brain injury is predicted for a $5.4 \mathrm{~atm}$ peak blast overpressure. However, the peak maximum shear stress and ICP in the brain indicated the occurrence of brain injury for the applied 17 atm peak blast overpressure.

\subsection{Influences of frequency-based loadings on the brain's dynamic responses}

To investigate the influence of the loading frequency on the responses of brain tissue, three different loading conditions have been employed, as shown in Figure 7. The loads are simplified as sine wave with the same amplitude of $17 \mathrm{~atm}$ and various frequencies of $10 \mathrm{kHz}, 100 \mathrm{kHz}$, and $1 \mathrm{MHz}$, respectively. 


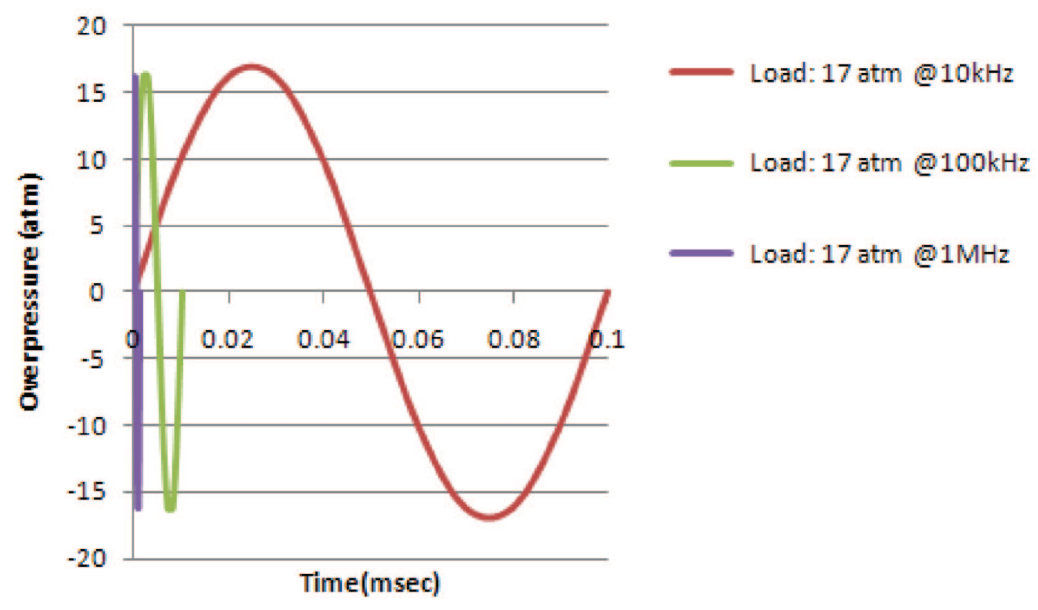

Figure 7. The sine wave loadings with the amplitude of $17 \mathrm{~atm}$ and various frequencies of $10 \mathrm{kHz}, 100 \mathrm{kHz}$, and $1 \mathrm{MHz}$.

Figure 8 has depicted the ICPs, maximum shear stresses and maximum principal strains of the brain corresponding to frequency-based loading inputs. It is clear that $10 \mathrm{kHz}$ loading caused a higher peak ICP, maximum shear stress, and

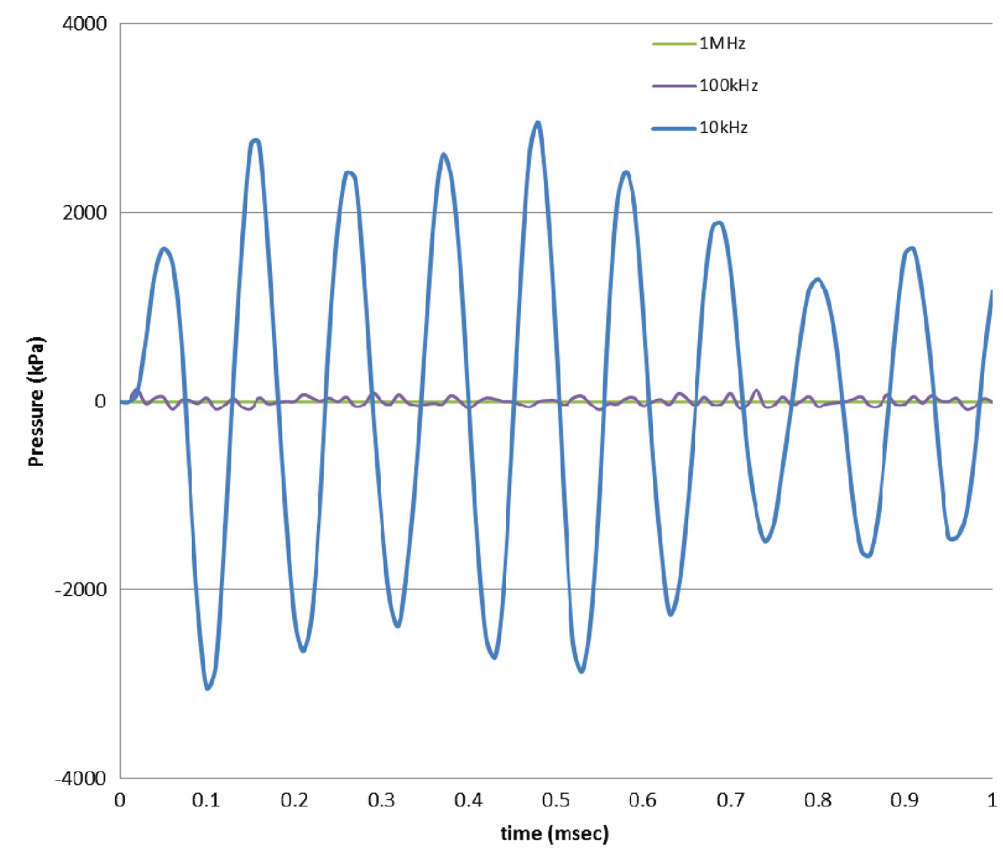

(a)

Figure 8. Influence of the applied loading frequency on the dynamic responses of the brain tissue subjected to $17 \mathrm{~atm}$ peak overpressure. 


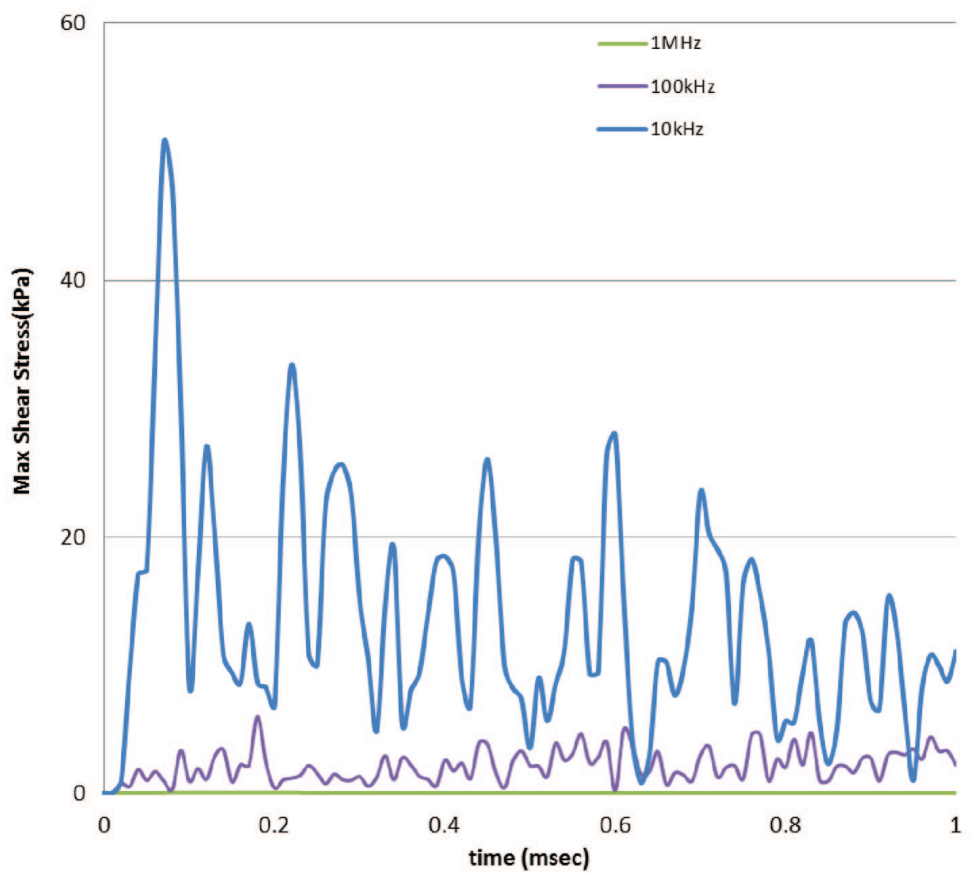

(b)

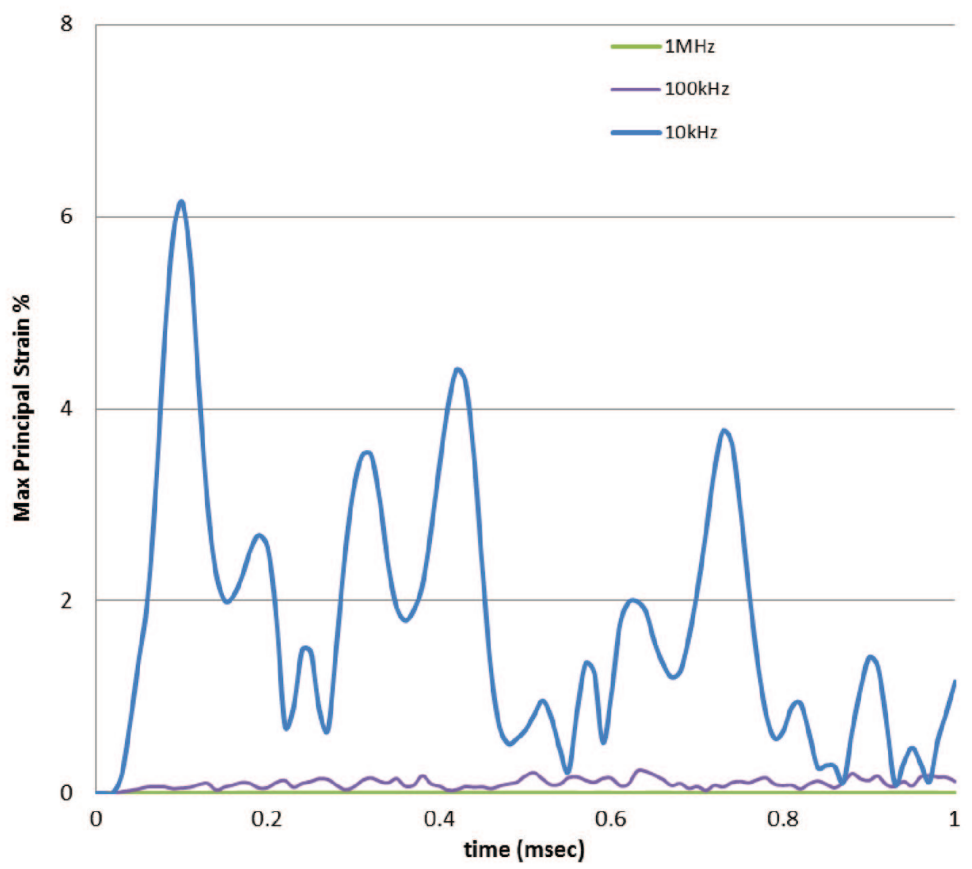

(c)

Figure 8. (continued) 
principal strain in the brain tissue, which are 16, 10, and 20 times higher than those resulted from a $100 \mathrm{kHz}$ sine wave load. Such significant differences are not apparent between the results of $100 \mathrm{kHz}$ and $1 \mathrm{MHz}$ loadings. The results from three frequency-varied input show that the brain behavior is very sensitive to the frequency of the applied load, especially around $10 \mathrm{kHz}$ level input. This indicates that blast loading directed from the range of $10 \mathrm{kHz}$ frequency may cause less dynamic responses on the brain, and therefore less TBI.

\section{Conclusions}

Animal studies have suggested that brain injury occurs as a direct result of blast waves [Courtney and Courtney, 2009]. However, the mechanism of blastinduced brain injury is not yet fully understood. Material models of brain tissue appropriate for large strains and a wide range of frequencies $(0.01 \mathrm{~Hz}-10$ $\mathrm{MHz}$ ) are a fundamental component of realistic numerical simulations of TBI. Existing material model of the brain doesn't cover such sweeping interval of frequencies.

In this study, a new set of parameters for the material model of the brain is derived by including both its hyperelastic and viscoelastic behavior under the frequency of $0.01 \mathrm{~Hz}$ up to $10 \mathrm{MHz}$. Two Ogden models and one Mooney-Rivlin model are used for the hyperelastic behavior of the brain. A Maxwell viscoelastic model is used to characterize its viscoelastic behavior and the parameters are determined based on the experimental data using GAs. The material models are implemented in a 2D head model to predict the brain's dynamic response subjected blast loadings. The results are summarized as the following:

- Contrary to current speculations in the literature, viscoelasticity plays a major role in the dynamic responses of the brain under blast loadings due to the appropriate incorporation of high frequency test data.

- The contribution of frequency-based viscoelasticity dominates the brain responses. The results suggest that simple Mooney-Rivlin model would be sufficient for representing the hyperelastic behavior of the brain tissue.

- A $10 \mathrm{kHz}$ loading caused more than 10 times the brain responses in terms of peak ICP, maximum shear stress, and principal strain in the brain tissue, compared to a $100 \mathrm{kHz}$ loading with the same magnitude.

- The applied 17 atm blast peak overpressure, corresponding to 50\% lethal dose for lung injury, will result in a 2-3 times increase of the brain responses in terms of ICPs, maximum shear stresses, and maximum principal strains, compared to a 5.4 atm blast peak overpressure.

Acknowledgments - This study is supported by the US Army Research Office (ARO), Contract No. W911NF-08-1-0483. There are no conflicts of interest of any kind in the work presented in this manuscript. 


\section{References}

Anderson, R. W. G., Brown, C. J., Blumbergs, P. C., Scott, G., Finney, J. W., Jones, N. R. and Mclean, A. J. [1999] "Mechanisms of axonal injury: An experimental and numerical study of a sheep model of head impact," Proc. International Conference on the Biomechanics of Impact, pp. 107-120.

Arbogast, K. B., Meaney, D. F. and Thibault, L. E. [1995] “Biomechanical characterization of the constitutive relationship for the brainstem," Proc. of the 39th Stapp Car Crash Conference, Number SAE 952716, pp. 153-159.

Arbogast, K. B. and Margulies, S. S. [1997] "Regional differences in mechanical properties of the porcine central nervous system," Proc. of the 41st Stapp Car Crash Conference, Number SAE 973336, pp. 293-300.

Arbogast, K. B. and Margulies, S. S. [1998] "Material characterization of the brainstem from oscillatory shear tests," Journal of Biomechanics 31(9), 801-807.

Bain, A. C. and Meaney, D. F. [2000] "Tissue-level thresholds for axonal damage in an experimental model of central nervous system white matter injury," Journal of Biomechanical Engineering 16, 615-622.

Baumgartner, D. and Willinger, R. [2005] "Numerical modeling of the human head under impact: New injury mechanisms and tolerance limits," IUTAM Proceedings on Impact Biomechanics: From Fundamental, Insights to Applications, pp. 195-203.

Bilston, L. E., Liu, Z. and Phan-Thien, N. [1997] “Linear viscoelastic properties of bovine brain tissue in shear," Biorheology 34(6), 377-385.

Bilston, L. E., Liu, Z. and Phan-Thien, N. [2001] "Large strain behavior of brain tissue in shear: Some experimental data and differential constitutive model," Biorheology 38(3), 335-345.

Bowen, I., Fletcher, E., Richmond, D., Hirsch, F. and White, C. [1968] “Biophysical mechanisms and scaling procedures applicable in assessing responses of the thorax energized by air-blast overpressures or by nonpenetrating missiles," Annals of the New York Academy of Sciences 152, 122-146.

Brands, D. W. A., Bovendeerd, P. H. M., Peters, G. W. M., Wismans, J. S. H. M., Paas, M. H. J. W. and van Bree, J. L. M. J. [1999] "Comparison of the dynamic behavior of the brain tissue and two model materials," Proc. of the 43rd Stapp Car Crash Conference, Number SAE 99SC21, pp. 57-64.

Brands, D. W. A., Bovendeerd, P. H. M., Peters, G. W. M. and Wismans, J. S. H. M. [2000] "The large shear strain dynamic behavior of in-vitro porcine brain tissue and the silicone gel model material," Proc. of the 44th Stapp Car Crash Conference, Number SAE 200001-SC17, pp. 249-260.

Brands, D. W. A., Bovendeerd, P. H. M., Peters, G. W. M. and Wismans, J. S. H. M. [2002] "On the potential importance of non-linear viscoelastic material modeling for numerical prediction of brain tissue response: Test and application," Stapp Car Crash Journal 46, 103-121.

Chafi, M. S., Karami, G. and Ziejewski, M. [2009] "Numerical analysis of blast-induced wave propagation using FSI and ALE multi-material formulations," International Journal of Impact Engineering 36, 1269-1275.

Chafi, M. S., Karami, G. and Ziejewski, M. [2010] "Biomechanical assessment of brain dynamic responses due to blast pressure waves," Annals of Biomedical Engineering 38(2), 490-504. 
Courtney, A. and Courtney, M. [2009] “A thoracic mechanism of mild traumatic brain injury due to blast pressure waves," Medical Hypotheses 72(1), 76-83.

Darvish, K. K. and Crandall, J. R. [2001] “Nonlinear viscoelastic effects in oscillatory shear deformation of brain tissue," Medical Engineering and Physics 23(9), 633-645.

Donnelly, B. R. and Medige, J. [1997] "Shear properties of human brain tissue," Journal of Biomechanical Engineering - T.ASME 119(4), 423-432.

El Sayed, T., Mota, A., Fraternali, F. and Ortiz, M. [2008] “Biomechanics of traumatic brain injury," Computer Methods in Applied Mechanics and Engineering 197(51-52), 4692-4701.

Estes, M. S. and McElhaney, J. H. [1970] "Response of brain tissue of compressive loading," Proc. of the 4th ASME Biomechanics Conference, Number 70-BHF-13.

Franceschini, G., Bigoni, D., Regitnig, P. and Holzapfel, G. A. [2006] “Brain tissue deforms similarly to filled elastomers and follows consolidation theory," Journal of Mechanics and Physics of Solids 54(12), 2592-2620.

Ganpule, S., Gu, L. and Chandra, N. [2010] "The effect of shock wave on a human head," Proc. of the ASME International Mechanical Engineering Congress and Exposition (IMECE) 2, 339-346.

Gefen, A. and Margulies, S. S. [2004] "Are in vivo and in situ brain tissues mechanically similar?" Journal of Biomechanics 37, 1339-1352.

Grujicic, M., Bell, W. C., Pandurangan, B. and Glomski, P. S. [2010] “Fluid/structure interaction computational investigation of the blast-wave mitigation efficacy of the advanced combat helmet," Journal of Materials Engineering and Performance, doi: 10.1007/ s11665-010-9724-z, 2010.

Ho, J. and Kleiven, S. [2007] “Dynamic response of the brain with vasculature: A three-dimensional computational study," Journal of Biomechanics 40(13), 3006- 3012.

Hoge, C. W., McGurk, D., Thomas, J. L., Cox, A. L., Engel, C. C. and Castro, C. A. [2008] "Mild traumatic brain injury in US soldiers returning from Iraq," NEJM 358, 453-463.

Horgan, T. J. and Gilchrist, M. D. [2003] “The creation of three-dimensional finite element models for simulating head impact biomechanics," International Journal of Crashworthiness 8(3), 1-14.

Horgan, T. J. and Gilchrist, M. D. [2004] "Influence of FE model variability in predicting brain motion and intracranial pressure changes in head impact simulations," International Journal of Crashworthiness 9(4), 401-418.

Hrapko, M., van Dommelen, J. A. W., Peters, G. W. M. and Wismans, J. S. H. M. [2006] "The mechanical behaviour of brain tissue: Large strain response and constitutive modelling," Biorheology 43, 623-636.

Hrapko, M., van Dommelen, J. A. W., Peters G. W. M. and Wismans, J. S. H. M. [2009] "On the consequences of nonlinear constitutive modelling of brain tissue for injury prediction with numerical head models," International Journal of Crashworthiness 14(3), 245-257.

Kang, H. S., Willinger, R., Diaw, B. M. and Chinn, B. [1997] “Modeling of the human head under impact conditions: A parametric study," Proc. of the 41st Stapp Car Crash Conference, SAE Paper No. 973338.

Kleiven, S. and Hardy, W. N. [2002] “Correlation of an FE model of the human head with local brain motion - Consequences for injury prediction, Proc. of the 46th Stapp Car Crash Conference, Society of Automotive Engineers, pp. 123-143.

Lippert, S. A., Rang, E. M. and Grimm, M. J. [2004] “The high frequency properties of brain tissue," Biorheology 41(6), 681-691. 
Liu, Z. S., Luo, X. Y., Lee, H. P. and Lu, C. [2007] “Snoring source identification using structure intensity method," Journal of Biomechanics 40(4), 861-870.

"LS-DYNA Theory Manual," [2006] Livermore Software Technol. Corp., Livermore, CA.

Mendis, K. K., Stalnaker, R. L. and Advani, S. H. [1995] “A constitutive relationship for large deformation finite element modeling of brain tissue," Transactions of ASME, Journal of Biomechanical Engineering 117, 279-285.

Miller, K. [1997] “Constitutive modeling of brain tissue: Experiment and theory,” Journal of Biomechanics 30(11-12), 1115-1121.

Miller, K. and Chinzei, K. [2002] "Mechanical properties of brain tissue in tension," Journal of Biomechanics 35(4), 483-490.

Moore, D. F., Jérusalem, A., Nyein, M., Noels, L., Jaffee, M. S. and Radovitzky, R. A. [2009] "Computational biology - modeling of primary blast effects on the central nervous system," Neuroimage 47(Suppl 2):T10-20.

Morrision, III-B., Cater, H. L., Wang, C. C-B., Thomas, F. C., Hung, C. T., Ateshian, G. A. and Sundstrom, L. E. [2003] "A tissue level tolerance criterion for living brain developed with an in vitro model of traumatic mechanical loading," Stapp Car Crash Journal 47, 93-105.

Moss, W. C., King, M. J. and Blackman, E. G. [2009] "Skull flexure from blast waves: A mechanism for brain injury with implications for helmet design," Phys. Rev. Lett. 103, 10.

Nicolle, S., Lounis, M. and Willinger, R. [2004] "Shear properties of brain tissue over a frequency range relevant for automotive impact situations: New experimental results," Stapp Car Crash Journal 48, 239-258.

Nicolle, S., Lounis, M., Willinger, R. and Palierne, J. F. [2005] "Shear linear behavior of brain tissue over a large frequency range," Biorheology 42, 209-223.

Pervin, F. and Chen, W. [2009] "Dynamic mechanical response of bovine gray matter and white matter brain tissues under compression," Journal of Biomechanics 42, 731-735.

Pervin, F. and Chen, W. [2011] "Effect of inter-species, gender, and breeding on the mechanical behavior of brain tissue," Neuroimage 54, S98-S102.

Prange, M. T. and Margulies, S. [2002] "Regional, directional and age-dependent properties of brain undergoing large deformation," Journal of Biomechanical Engineering 124, 244-252.

Shuck, L. and Advani, S. [1972] "Rheological response of human brain tissue in shear," Journal of Basic Engineering 94, 905-911.

Takhounts, E. G., Crandall, J. R. and Darvish, K. K. [2003] “On the importance of nonlinearity of brain tissue under large deformations," Stapp Car Crash Journal 47, 107-134.

Taylor, P. A. and Ford, C. C. [2009] "Simulation of blast-induced early-time intracranial wave physics leading to traumatic brain injury," Journal of Biomechanical Engineering 131, 061007-1-061007-5.

Ward, C. C., Chan, M. and Nahum, A. M. [1980] "Intracranial pressure - A brain injury criterion," Proc. of the 24th Stapp Car Crash Conference, SAE Paper No. 801304.

Zhang, L., Yang, K. H. and King, A. I. [2001] “Comparison of brain responses between frontal and lateral impacts by finite element modeling," Journal Neurotrauma 18(1), 21-30. 